\title{
Identification of Negative Regulator of Interleukin-3 (NIL-3) in Bone Marrow
}

\author{
Yasuhiro Adachi $^{1 *}$, Kenkichi Sugimoto ${ }^{1}$, Asako K. Sato ${ }^{1}$, and Kazuhiro John Mori² \\ ${ }^{1}$ Department of Cell Science, Graduate School of Science and Technology, Niigata, 950-2181, Japan and \\ ${ }^{2}$ Department of Molecular and Cellular Biology, Faculty of Science, Niigata University, Niigata, 950-2181, \\ Japan
}

\begin{abstract}
We have reported that an inhibitor of interleukin-3 (NIL-3) is produced from murine bone marrow cells in response to excess stimulation of interleukin-3. In this report, we attempted the purification of the NIL-3 activity from bone marrow culture supernatant in the presence of interleukin-3. The purified NIL-3 activity was a protein with relative molecular weight of $54.5 \mathrm{kDa}$ (SDS-PAGE), which inhibited the growth of IL-3 dependent DA-1 cell growth in a dose dependent manner. The N-terminal amino acid sequence of purified NIL-3 activity was determined to be homologous to beta-2 glycoprotein I (apolipoprotein H: APO-H). The gene expression of APO-H was detected by nested-PCR in STIL-3 C5-CM stimulated total bone marrow cells and STIL-3 C5-CM stimulated bone marrow fraction 2 (Fr. 2) which has been reported as a hematopoietic stem cell rich fraction. These observations indicate the possibility that the APO-H is the NIL-3 which was produced from bone marrow cells in response to excess IL-3 stimuli.
\end{abstract}

Key words: Interleukin-3/inhibitor/apolipoprotein H/hematopoiesis

The growth and differentiation of hematopoietic stem cells is controlled by the hematopoietic microenvironment as well as by soluble growth factors (Metcalf, 1986; Wolf, 1979). Accumulated evidence shows the multifunction of interleukin-3 (IL-3) on hematopoiesis. The growth and/or differentiation inducing activity of hematopoietic progenitors or stem cells, and their involvement in positive feedback mechanisms in mouse granulopoiesis has been reported (Miyashita et al., 1991; Tsuji et al., 1994).

However, in addition to stimulatory factors, negative feedback mechanisms and producing suppressive factors to compensate for the excess stimuli of IL-3 are also essential for the maintenance of stable state of hematopoiesis. Several hematopoietic inhibitors have been reported, such as stem cell inhibitor (MIP-1 $\alpha$ ) (Graham et al., 1990; Lord et al., 1976; Wolpe and Cerami, 1989), lactoferrin (Broxmeyer $e t$ al., 1984), TGF- $\beta$ (de Larco and Todaro, 1978; Holley et al., 1980; Tucker et al., 1984), inhibitors of erythroid and

*To whom correspondence should be addressed: Yasuhiro Adachi, First Department of Anatomy, School of Medicine, Yamaguchi University, 1-11, Minami-kogushi, Ube, Yamaguchi, 755-8505, Japan.

Tel: +81-836-22-2202, Fax: +81-836-22-2203

E-mail: adachiy@yamaguchi-u.ac.jp

Abbreviations: IL-3, interleukin-3; NIL-3, negative regulator of IL-3; APO-H, apolipoprotein H; FBS, fetal bovine serum. granulocyte-macrophage progenitors (Axelrad et al., 1981; Broxmeyer et al., 1981; Broxmeyer et al., 1986), IL-1 inhibitors (Carter et al., 1990; Hannum et al., 1990), and inhibitor of IL-3 dependent cells (Lenfant et al., 1989; Pluthero et al., 1990).

Yoshida and Seki (Yoshida and Seki, 1985) induced T cell leukemia, L8313, in mice. IL-3 producing leukemic T cell line (STIL-3 C5) was established from the spleen cells of L8313 bearing C3H mice (Sawada et al., 1988). We found that IL-3 activity in the bone marrow of L8313 mouse was lower than that of the spleen, although the existence ratio of IL-3 producing leukemic T cells in the bone marrow and the spleen was almost the same. When STIL-3 C5 cells were co-cultured with normal bone marrow cells, IL-3 activity in the culture supernatant was lower than when STIL3 C 5 cells were cultured alone. When these conditioned media (CM) were heated at $70^{\circ} \mathrm{C}$ for 30 minutes, IL-3 activity was recovered, indicating the existence of heat-labile IL-3 inhibitor, named NIL-3, in the CM of bone marrow cells culture in the presence of excess IL-3 stimuli (Sugimoto et al., 1992). In the present report, the purification of NIL-3, its physiological activity to IL-3 dependent cells and its gene expression in bone marrow cells were described. 


\section{Materials and Methods}

\section{Mice}

Female mice of $\mathrm{C} 3 \mathrm{H} / \mathrm{HeNSlc}$ strain were purchased from Japan SLC, Inc. (Shizuoka, Japan), housed under specific pathogen free conditions, and used at 8-10 weeks of age.

\section{Cell lines}

An IL-3 producing T cell line derived from L8313 leukemic mice, STIL-3 C5 (Sawada et al., 1988), was maintained in RPMI 1640 medium supplemented with 5\% (v/v) FBS in a humidified atmosphere. Mouse IL-3 dependent cell line DA-1 (Ihle, 1985; Ihle and Askew, 1989) was maintained in RPMI1640 medium supplemented with $10 \%$ (v/v) FBS and $10 \%$ (v/v) STIL-3 C5-CM as a source of IL-3. During cell proliferation assay, the STIL-3 C5-CM was replaced with recombinant murine IL-3 (Kirin co. Ltd., Tokyo, Japan).

\section{Media conditioned by STIL-3 C5 cells as source of IL-3}

STIL-3 C5 cells was cultured in the growth medium at a density of $1 \times 10^{6}$ cells $/ \mathrm{mL}$ for 3 days. The $\mathrm{CM}$ was collected and centrifuged at $600 \times \mathrm{g}$ for $15 \mathrm{~min}$ at $4^{\circ} \mathrm{C}$, sterilized by passing through $0.22 \mu \mathrm{m}$ cellulose-acetate membrane (Millipore, Bedford, MA, U.S.A.), and stored at $-30^{\circ} \mathrm{C}$ until use.

\section{Purification of the inhibitory factor of IL-3 (NIL-3)}

Purification of NIL-3 was performed according to the method described previously (Sugimoto et al., 1992), with some modifications to deal with the large amount of the sample.

To induce the production of NIL-3, total bone marrow cells from $\mathrm{C} 3 \mathrm{H} / \mathrm{HeNSlc}$ mice were stimulated with growth medium (RPMI-1640 medium supplemented with 50\% (v/v) STIL-3 C5-CM, 5\% (v/v) FBS, and $10 \mathrm{mM}$ HEPES) containing excess IL-3 at $37^{\circ} \mathrm{C}$ for 4 days. After 4 days, the $\mathrm{CM}$ was centrifuged at $15000 \times \mathrm{g}$ for $30 \mathrm{~min}$ at $4^{\circ} \mathrm{C}$, then aprotinin (Wako Pure Chemicals, Osaka, Japan) was added at a final concentration of 50 units $/ \mathrm{mL}$. The $\mathrm{CM}$ was stored at $-80^{\circ} \mathrm{C}$ as a crude sample.

The stored sample was thawed and saturated with $4.25 \mathrm{M}$ ammonium sulfate, and stirred for 24 hours at $4^{\circ} \mathrm{C}$. The sample was then centrifuged at $15000 \times \mathrm{g}$ for $20 \mathrm{~min}$ at $4^{\circ} \mathrm{C}$. The precipitate was dissolved in $0.1 \mathrm{M}$ phosphate buffer ( $\mathrm{pH}$ 7.0) supplemented with $0.5 \mathrm{mM}$ dithiothreitol (DTT), 0.1mM EDTA, and dialyzed against a large volume of the same buffer at $4^{\circ} \mathrm{C}$ (step 1 sample).

For the hydrophobic interaction chromatography, step 1 sample was saturated with $0.8 \mathrm{M}$ ammonium sulfate, and applied to HPLC column (TSKgel phenyl-5PW, $21.5 \mathrm{~mm} \mathrm{ID \times 150}$ $\mathrm{mm}$, Tosoh, Tokyo, Japan). Elution of proteins was carried out with a linear gradient of ammonium sulfate (from $0.8 \mathrm{M}$ to 0 $\mathrm{M}$ ), at a flow rate of $4 \mathrm{~mL} / \mathrm{min}$. The positive fraction of NIL-3 activity (P1 fraction) was concentrated and dialyzed against 20 $\mathrm{mM}$ Tris- $\mathrm{HCl}$ (pH 7.0) containing $0.5 \mathrm{mM}$ DTT, $0.1 \mathrm{mM}$
EDTA (step 2 sample).

For the third step of purification, ion-exchange chromatography was carried out. Step 2 sample was applied to TSKgel DEAE-5PW (21.5 mm ID $\times 150 \mathrm{~mm}$, Tosoh, Tokyo, Japan) and Mono-Q HR 5/5 (5 mm ID $\times 50 \mathrm{~mm}$, Amersham Pharmacia Biotech AB, Uppsala, Sweden). Proteins were eluted with a linear gradient of $\mathrm{NaCl}(0 \mathrm{M}$ to $1 \mathrm{M})$, at a flow rate of $4 \mathrm{~mL} /$ $\mathrm{min}$ and $1 \mathrm{~mL} / \mathrm{min}$, respectively. The positive fraction of NIL-3 activity (X1 fraction) was concentrated and dialyzed against 10 $\mathrm{mM}$ MES (pH 6.0) containing $0.5 \mathrm{mM}$ DTT and $0.1 \mathrm{mM}$ EDTA (step 3 sample).

Step 3 sample was applied to Mono-S HR 5/5 (5 mm ID $\times 50$ $\mathrm{mm}$, Amersham Pharmacia Biotech AB, Uppsala, Sweden) for further purification. Proteins were eluted with a linear gradient of $\mathrm{NaCl}(0 \mathrm{M}$ to $1 \mathrm{M})$, at a flow rate of $1 \mathrm{~mL} / \mathrm{min}$. The positive fraction of NIL-3 activity (V3 fraction) was concentrated and the buffer was exchanged to $10 \mathrm{mM}$ sodium phosphate buffer (pH 7.0) using Centricon-30 (Millipore, Bedford, MA, U.S.A.) (step 4 sample).

Concentrated step 4 sample was applied to HiTrap Heparin (16 mm ID $\times 25$ mm, Amersham Pharmacia Biotech AB, Uppsala, Sweden). The positive fraction of NIL-3 activity (W2 fraction) was concentrated and the buffer was exchanged to 50 $\mathrm{mM}$ sodium phosphate buffer ( $\mathrm{pH} 6.8$ ) containing $0.5 \mathrm{M} \mathrm{NaCl}$, $0.5 \mathrm{mM}$ DTT and $0.1 \mathrm{mM}$ EDTA by Centricon-30 as step 5 sample.

After heparin affinity chromatography, we performed gel filtration chromatography as the final purification step. Step 5 sample was applied to G3000SWXL $(7.8 \mathrm{~mm}$ ID $\times 300 \mathrm{~mm}$, Tosoh, Tokyo, Japan). NIL-3 activity was concentrated in relative molecular weight of about $60 \mathrm{kDa}(\mathrm{K} 2)$ fraction, as we have reported previously (>50 kDa) (Sugimoto et al., 1992). The eluted fraction (step 6 sample) was concentrated and the buffer was exchanged to PBS- by Centricon-30, and then sterilized with $0.22 \mu \mathrm{m}$ cellulose-acetate membrane and used in DA-1 cell proliferation assay.

Fractionated and concentrated NIL-3 activity was analyzed by SDS-PAGE, and N-terminal amino acid sequence of the main band was determined.

The protein concentration at each purification step was determined by Lowry method or Micro BCA Assay Kit (Pierce, Rockford, U.S.A.) with BSA standards.

\section{NIL-3 activity of recombinant murine IL-3 stimulation}

Total bone marrow cells were stimulated with recombinant murine IL-3 (Kirin Co., Ltd., Tokyo, Japan) at a final cell density of $1 \times 10^{6}$ cells $/ \mathrm{mL}$ for 4 days. The NIL-3 activity of collected CM was determined by DA-1 cell proliferation assay, as described below.

\section{Total RNA extraction and RT-PCR}

Total RNA was extracted from total or fractionated normal bone marrow cells, L8313 leukemic liver, spleen and total bone marrow using TRIZOL LS Reagent (Invitrogen Corp., Carls- 
bad, CA, U.S.A.). Two micrograms of total RNA was reversetranscribed using Omniscript reverse transcriptase (Qiagen K.K., Tokyo, Japan). RT-PCR was carried out under standard conditions for 30 cycles with denaturation at $94^{\circ} \mathrm{C}$ for $1 \mathrm{~min}$, annealing at $65^{\circ} \mathrm{C}$ for $1 \mathrm{~min}$, extension at $72^{\circ} \mathrm{C}$ for $1 \mathrm{~min}$, and final extension at $72^{\circ} \mathrm{C}$ for $5 \mathrm{~min}$. We used custom primers according to murine apolipoprotein $\mathrm{H}$ mRNA sequence (GenBank NM-013475).

Primer sequences for 1st-PCR were 5'-CGGGATCCATGGTTTCCCCGGTGCTC-3' (sense-1, BamHI site plus position 32-49), and 5' -CCCAAGCTTTCAGCACGGTGTCAGTTC-3' (antisense-1, position 1052-1069 plus HindIII site). Following the 1st-PCR, we performed 2nd (nested)-PCR using $0.2 \mu \mathrm{l}$ of 1 st PCR product in a reaction volume of $20 \mu \mathrm{l}$, in the same conditions under 1st-PCR. Primer sequences for nested-PCR were 5'-CGGGATCCGGACGGATCTGTCCGAAG-3' (sense2, BamHI site plus position 89-106) and 5'-GATAGTGCCATCTCTGCAATGAGC-3' (antisense-2, position 968-991).

Apolipoprotein-H is known to be produced in liver (Nonaka et al., 1992), therefore, reverse transcripts of $\mathrm{C} 3 \mathrm{H} / \mathrm{HeN}$ liver total RNA were used as positive control of amplified products in bone marrow cells. For the internal control, we used amplified product of $\beta$-actin. Primer sequences for $\beta$-actin were 5'TCAGAAGGACTCCTATGTGG-3' (sense, position 224-243) and 5'-TCTCTTTGATGTCACGCACG-3' (antisense, position 704-723) (Tokunaga et al., 1986). Amplified cDNA products were analyzed in $1 \%(\mathrm{w} / \mathrm{v})$ agarose gel and stained with ethidium bromide.

\section{Preparation of recombinant $\mathrm{APO}-\mathrm{H}$}

To prepare the recombinant protein, we amplified the cDNA encoding murine apolipoprotein $\mathrm{H}$ from the normal $\mathrm{C} 3 \mathrm{H} / \mathrm{HeN}$ liver cDNA library by RT-PCR. RT-PCR was carried out with custom primers (sense-2 and antisense-1, described above) which have BamHI and HindIII restriction sites at the 5' and 3' ends, respectively. PCR was performed for 35 cycles with denaturation at $94^{\circ} \mathrm{C}$ for $1 \mathrm{~min}$, annealing at $65^{\circ} \mathrm{C}$ for $1 \mathrm{~min}$, extension at $72^{\circ} \mathrm{C}$ for $1 \mathrm{~min}$, and final extension at $72^{\circ} \mathrm{C}$ for 5 $\min$.

The PCR product was purified and cloned into pBluescript SK(-) plasmid by TA-cloning. The cDNA insert encoding APO-H was prepared by digesting the cDNA with BamHI and HindIII, and purified by electrophoresis. The BamHI/HindIII cDNA fragment was cloned into BamHI/HindIII digested pFASTBAC HTb donor plasmid containing $6 \times$ histidine $(6 \times$ his) tag and rTEV protease recognition sequence, and transposed into the baculovirus expression vector system (Bac-To-Bac Baculovirus Expression System: Invitrogen Corp., Carlsbad, CA, U.S.A.).

The $6 \times$ his tagged-recombinant protein was purified from $\mathrm{Sf} 9$ cell lysate by immobilized metal affinity chromatography, and 6×his tagged-recombinant APO-H was eluted in buffer containing $500 \mathrm{mM}$ imidazole. The eluted fraction was concentrated with phosphate buffered saline (PBS ${ }^{-}$) by Centrocon-30.
The protein concentration was determined by Micro BCA kit (Pierce) with BSA standards.

\section{DA-1 cell proliferation assay of IL-3 antagonism}

To examine the inhibitory activity of NIL-3, cell proliferation assay was carried out using IL-3 dependent DA- 1 cells. Briefly, DA-1 cells were cultured at the final concentration of $4 \times 10^{3}$ cells/mL in RPMI 1640 containing 10\% (v/v) FBS, 10 ng/mL rmIL-3, and heated $\left(70^{\circ} \mathrm{C}, 30 \mathrm{~min}\right)$ or not-heated test protein sample in 96-well plate for 96 hours. After 96 hours, cells were stained with $2 \%$ trypan blue and the number of living cells was counted.

Since the partially purified NIL-3 contains a small amount of native IL-3, the NIL-3 activity was calculated by comparison of the growth of DA-1 cells in the presence of normal test sample with heated $\left(70^{\circ} \mathrm{C}, 30 \mathrm{~min}\right)$ sample (Sugimoto et al., 1997)

Formula-1 is:

Inhibition $(\%)=100 \times\{1-($ Growth of DA- 1 cells with native test sample) / (Growth of DA-1 cells with heated test sample)\}

From purification step 4, NIL-3 activity was calculated by formula-2, since the NIL-3 activity was separated from IL-3 activity.

Formula-2 is:

Inhibition $(\%)=100 \times\{1-($ Growth of DA- 1 cells with native test sample plus rmIL-3) / (Growth of DA1 cells with plus rmIL-3)\}

\section{Results}

\section{Induction of NIL-3 activity by recombinant murine IL-3}

For induction of the NIL-3 activity, we stimulated the bone marrow cells with STIL-3 C5-CM as the source of IL-3. However, as the STIL-3 C5-CM still contains various proteins including serum proteins, we attempted to stimulate the bone marrow cells with recombinant murine IL-3 alone. DA-1 cell proliferation assay showed that comparatively high NIL-3 activity was induced by the stimulation with $>80 \mathrm{ng} / \mathrm{mL}$ of recombinant murine IL-3 (Fig. 1).

\section{Physiochemical properties of NIL-3}

The NIL-3 purification steps are summarized in Table I. The NIL-3 is produced by a certain population of bone marrow cells in response to excess stimulation of IL-3 (Sugimoto et al., 1997), and therefore the crude sample inevitably contains large amounts of IL-3. As NIL-3 was shown to be heat-labile (Sugimoto et al., 1997), NIL-3 activity was calculated from the comparison of heated sample $\left(70^{\circ} \mathrm{C}\right.$ for 30 min) with not-heated sample (formula-1), until NIL-3 activity was separated from IL-3 activity at step 4 (formula-2).

At the sixth step of purification, the NIL-3 activity was 


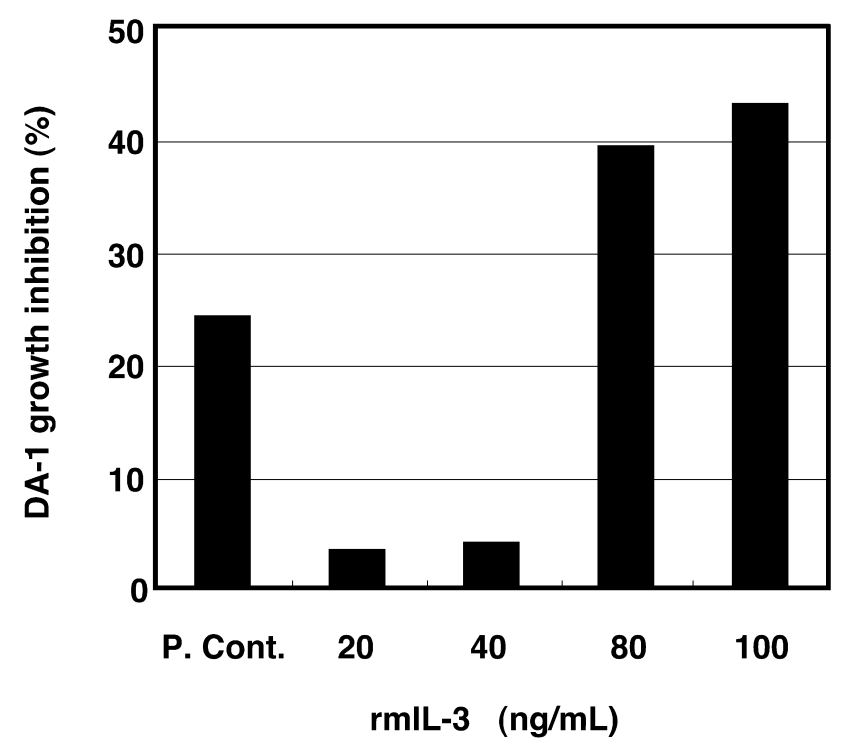

Fig. 1. Induction of NIL-3 activity by recombinant IL-3 stimulation. Results are indicated as a percentage (mean, $n=3$ ) of normal DA-1 culture condition. P. Cont.: 50\% STIL-3 C5-CM stimulated bone marrow CM was tested by DA-1 cell proliferation assay.

fractionated in $\mathrm{K} 2$ fraction. The relative molecular weight of this fraction was $60 \mathrm{kDa}$ (calibrated by Gel filtration calibration kit, Amersham Pharmacia Biotech AB, Uppsala, Sweden) (Fig. 2a, b). The purified protein at each purification step inhibited the growth of IL-3 dependent DA-1 cells in a dose dependent manner (Fig. 3).

However, when SDS-PAGE of K2 fraction was carried out, a major band was found at the relative molecular weight of $54.5 \mathrm{kDa}$ (Fig. 4) in silver-stained gel (calibrated by LMW electrophoresis calibration kit, Amersham Pharmacia Biotech AB, Uppsala, Sweden). This appears be the result of the overlapping of two or more peaks including the $54.5 \mathrm{kDa}$ peak by decrease of column resolution. The $>60$
$\mathrm{kDa}$ fractions (K0 and $\mathrm{K} 1$ ) had no or very low NIL-3 activity (Fig. 2b), and the $60 \mathrm{kDa}$ protein in silver-stained gel was BSA (data not shown).

Amino acid sequence of the $54.5 \mathrm{kDa}$ protein was determined. The sequence of the first 8 amino acid from $\mathrm{N}$-terminal was GRTCPKPD, which was homologous with the first 8 amino acid sequence of the mature form of bovine beta-2glycoprotein-I (apolipoprotein $\mathrm{H})$.

\section{PCR analysis}

Apolipoprotein-H (APO-H) is a plasma protein which has been reported to bind to various negatively charged substances, such as heparin and phospholipids. While the purified NIL-3 was homologous with bovine APO-H, there was a possibility that the NIL-3 might also be homologous with murine APO-H, because only a single amino acid difference existed in the first 8 amino acids of murine APO-H, which were GRICPKPD (Nonaka et al., 1992). Therefore, we performed nested-PCR to investigate the gene expression of murine APO-H in bone marrow cells.

By RT-PCR, murine APO-H gene expression was detected at predicted size (903 bp) in STIL-3 C5-CM stimulated total bone marrow cells, but not in normal total bone marrow cells (Fig. 5). Moreover, when the total bone marrow cells were fractionated by Percoll density-gradient centrifugation, APO-H gene expression was detected in STIL-3 C5CM stimulated fraction (Fr.) $2(1.064<\rho<1.074)$, which has been reported to be a hematopoietic stem cell rich fraction (Sugiura et al., 1988).

When the amplified cDNA fragment in bone marrow by nested-PCR was sequenced, it showed that the sequence was $99 \%$ homologous to murine APO-H (data not shown).

In order to investigate the in vivo gene expression of APO-H, we used total RNA of the liver, spleen and the total bone marrow cells from L8313 leukemia bearing mice. The gene expression of APO-H was detected in these organs (Fig. 6a, b and c). The IL-3 producing leukemic T-cell line,

Table I. SUMMARY OF THE PURIFICATION OF NIL-3 ACTIVITY

\begin{tabular}{|c|c|c|c|c|c|}
\hline Step No. & & $\begin{array}{l}\text { Protein } \\
\mathrm{mg}\end{array}$ & $\begin{array}{l}\text { Yield } \\
\%\end{array}$ & $\begin{array}{l}\text { Specific activity } \\
\text { units/mg }\end{array}$ & $\begin{array}{c}\text { Purification } \\
\text { fold }\end{array}$ \\
\hline 0 & Crude sample (conditioned medium) & 12075 & 100.00 & 1.74 & 1.00 \\
\hline 2 & Hydrophobic interaction chromatography & 1526 & 12.64 & 2.80 & 1.56 \\
\hline $3-1$ & Anion exchange chromatography 1 (DEAE) & 652.9 & 4.69 & n. t. & n. t. \\
\hline $3-2$ & Anion exchange chromatography 2 (Mono-Q) & 555.7 & 1.80 & 45.05 & 25.03 \\
\hline 4 & Cation exchange chromatography & 14.8 & 0.16 & 90.91 & 50.51 \\
\hline 5 & Heparin affinity chromatography & 9.804 & 0.081 & 100.00 & 55.56 \\
\hline 6 & Gel filtration chromatography & 0.155 & 0.0013 & 1250.00 & 694.44 \\
\hline
\end{tabular}

a) Specific activity: NIL-3 activity was tested by DA-1 cell proliferation assay as described in Materials and Methods. One unit of NIL-3 activity was defined as the activity which inhibit the DA-1 growth to $50 \%$ of control. ${ }^{\text {b) }}$ n. t.: not tested 
a)

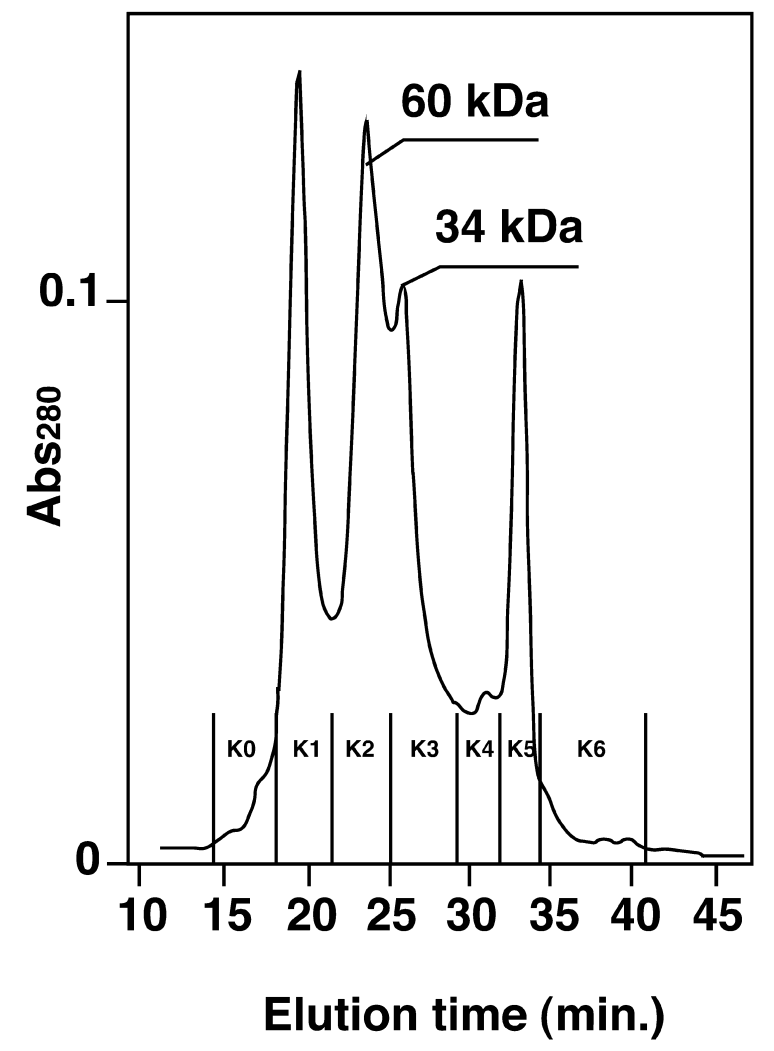

b)

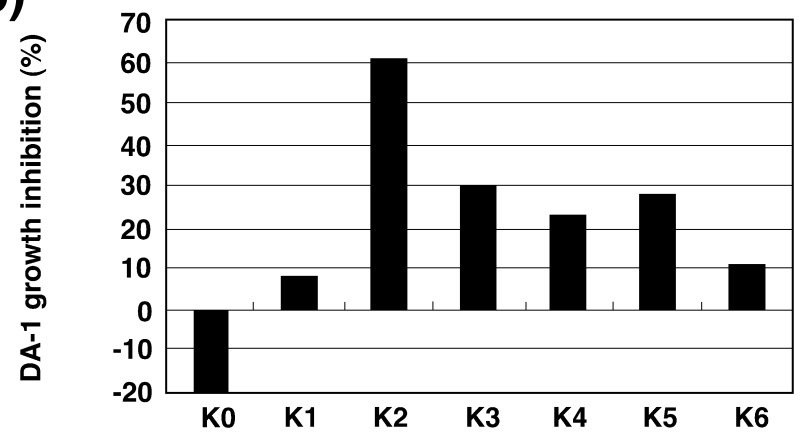

Fig. 2. Result of gel filtration chromatography. The final purification steps of NIL-3 activity are indicated. Gel filtration chromatography was performed using G3000SWXL column (a). The NIL-3 activity of fractionated sample at each step is indicated below (b).

STIL-3 C5, which was used for the preparation of conditioned medium as the source of IL-3, did not produce APOH (Fig. 6d).

\section{Effect of recombinant murine APO-H on DA-1 cell proliferation assay}

The purified recombinant protein was electrophoresed in $10 \%$ polyacrylamide gel and silver stained (Fig. 7). When

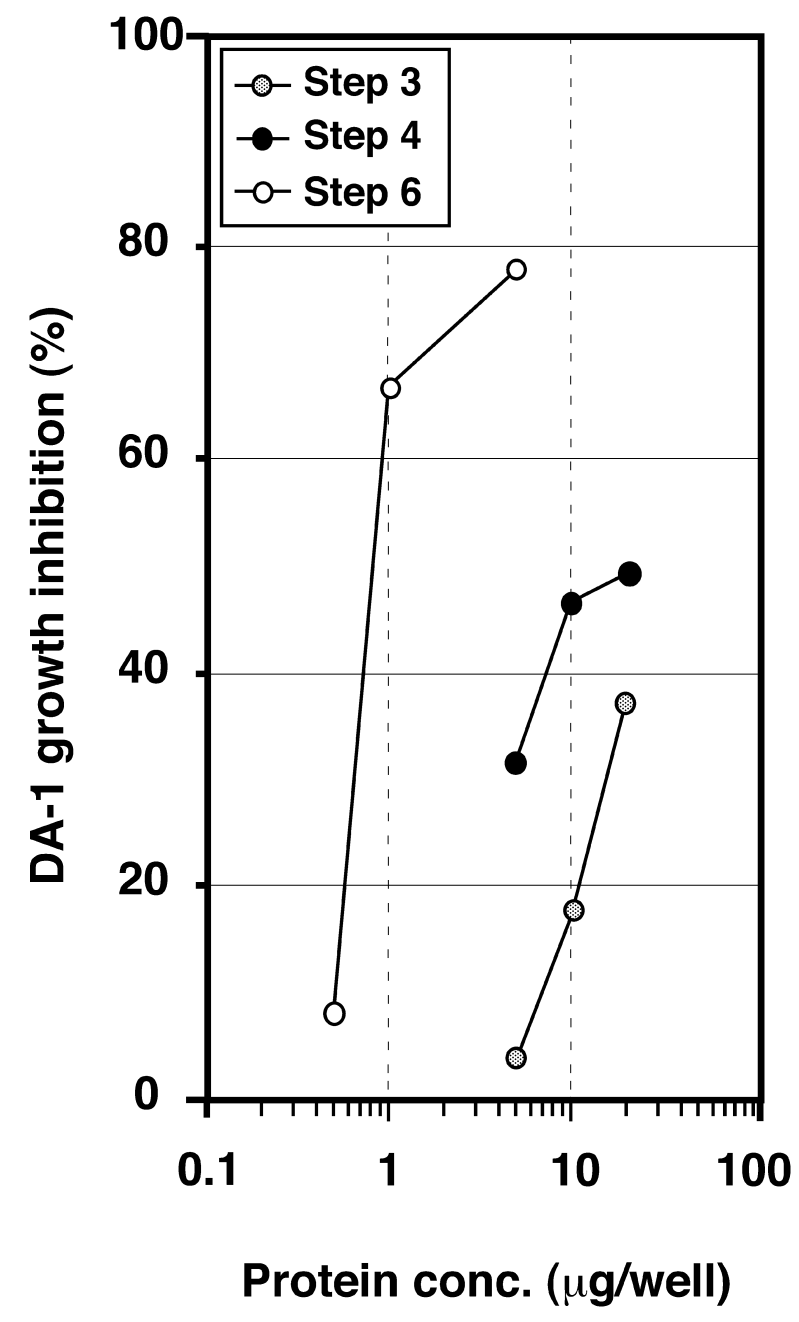

Fig. 3. Dose vs. inhibitory effect of purified protein on the DA-1 cell proliferation assay. Effect of purified NIL-3 activity on the growth of IL-3 dependent DA-1 cells was tested. Results are expressed as a percentage (mean, $n=3$ ) of STIL-3 C5-CM stimulated positive control group.

the human APO-H was produced in Sf9 insect cell, the relative molecular weight of recombinant protein was $43 \mathrm{kDa}$ although the native APO-H is $50 \mathrm{kDa}$ (Igarashi et al., 1996). In this experiment, the relative molecular weight of recombinant murine APO-H was predicted to be approximately 45 $\mathrm{kDa}(43 \mathrm{kDa}+2 \mathrm{kDa}: 6 \times$ his tag and spacer sequence in pFASTBAC HTb plasmid), and was actually detected at 45 kDa.

The purified protein solution containing recombinant APO-H was tested for the NIL-3 activity by DA-1 cell proliferation assay. The inhibition percentage of DA-1 cell growth was $14.2 \%$ (Fig. 8).

\section{Discussion}

Interleukin-3 (IL-3) plays essential role in the proliferation and differentiation of hematopoietic stem cells and pro- 


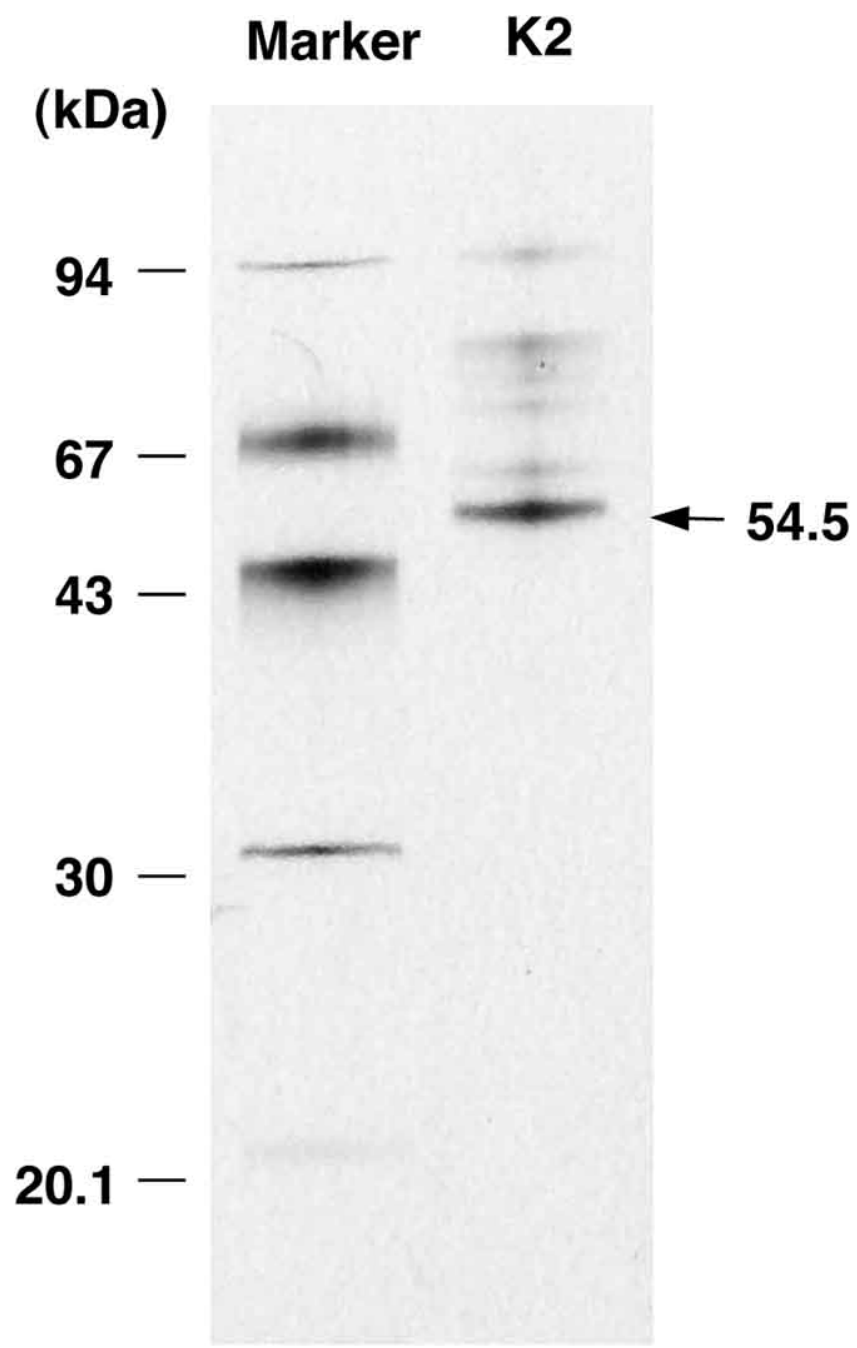

Fig. 4. SDS-PAGE of purified NIL-3 containing sample. SDS-PAGE of $\mathrm{K} 2$ fraction was carried out in $10-20 \%$ polyacrylamide gradient gel. The purified K2 sample and low molecular weight marker were applied at 100 ng/lane, and electrophoresed gel was silver-stained.

genitors (Delorme and Daniels, 1992; Spivak et al., 1985). Especially in hematopoietic progenitors, IL-3 stimulates the proliferation and/or differentiation together with lineage specific cytokines such as Epo, G-, M-, and GM-CSF. However, not only the stimulatory factors but also the suppressive factors or negative feedback mechanisms are essential for the long-term maintenance of the stable hematopoiesis (Goldwasser et al., 1983). To compensate for the excess stimuli for hematopoiesis by stimulatory factors, negative regulatory factors may be produced which act as antagonists to the production of the stimulatory factors. If the hematopoietic stem cells undergo unlimited differentiation, it will result in the depletion of the stem cell reservoir without such negative regulatory mechanisms. Recently, several factors have been reported which act as antagonists or sup-

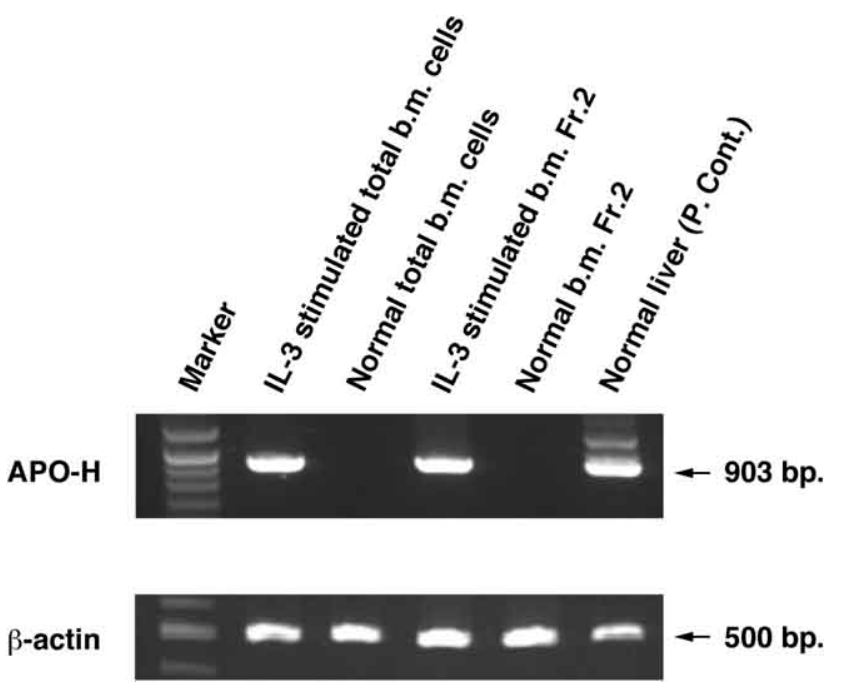

Fig. 5. PCR analysis of APO-H gene expression in bone marrow cells. In order to detect the gene expression of APO-H in bone marrow cells, nested-PCR was carried out. PCR cycles for the detection of the amplified cDNA of b-actin and APO-H were 30 cycles amplification. The amplified cDNA fragment was electrophoresed in $1 \%$ agarose gel, in $0.5 \times \mathrm{TBE}$ buffer. The nested-PCR product of APO-H cDNA was detected at predicted size (903 bp) in STIL-3 C5-CM stimulated total bone marrow cells and stimulated Fr. 2 cells, which was fractionated by Percoll density-gradient centrifugation. The amplification product of $\beta$-actin (500 bp.) was used as the internal control.

pressors of IL-3 activity (Lenfant et al., 1989; Pluthero et al., 1990).

We attempted to purify the NIL-3 activity from $\mathrm{C} 3 \mathrm{H} / \mathrm{HeN}$ bone marrow cell-conditioned medium stimulated with IL-3 producing STIL-3 C5-CM. The STIL-3 C5-CM consists of a number of proteins including serum protein and native IL3. Therefore, we stimulated the bone marrow cells with recombinant murine IL-3 alone. DA-1 cell proliferation assay revealed that a comparatively high NIL-3 activity was induced when bone marrow cells were stimulated with $>80$ $\mathrm{ng} / \mathrm{mL}$ of recombinant murine IL-3 (Fig. 1). The IL-3 activity of STIL-3 C5-CM calculated from this result was approximately $160 \mathrm{ng} / \mathrm{mL}$.

The purified NIL-3 was a protein of a relative molecular weight of $54.5 \mathrm{kDa}$ (SDS-PAGE). The N-terminal amino acid sequence was homologous to beta-2-glycoprotein I (apolipoprotein H: APO-H).

APO-H is a plasma protein produced from the liver, which has five SCR domains found mostly in the regulatory proteins of the complement system (Reid and Day, 1989). Several possible roles of APO-H were also reported, including the hematopoietic suppressive effect in bovine ( $\mathrm{Li}$ and Congote, 1991), the relation to atherosclerosis in human and murine (George et al., 1999; Shoenfeld et al., 2000), the participation in the production of autoantibodies (McNeil et al., 1990), and the prevention of intrinsic blood coagulation through binding to the anionic phospholipids on the surface 
a) Liver

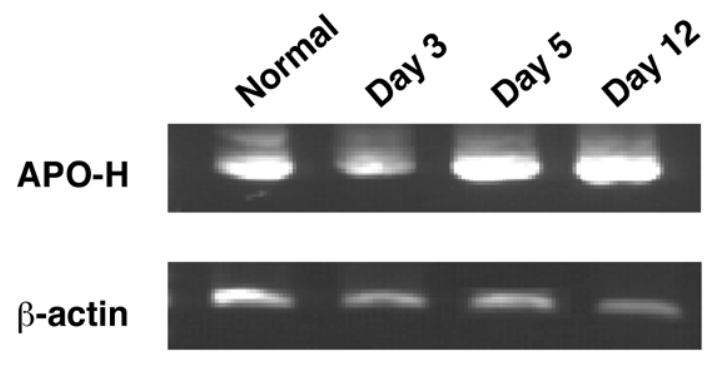

b) Spleen

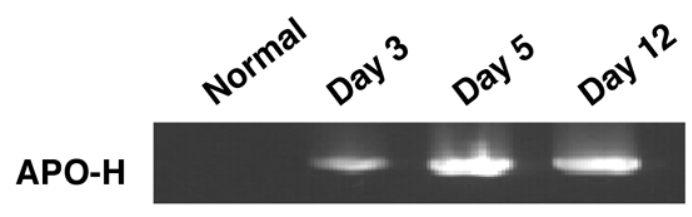

$\beta$-actin

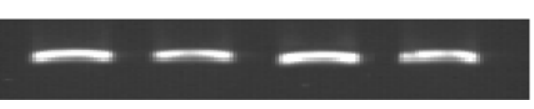

$903 \mathrm{bp}$.

$500 \mathrm{bp}$.

\section{c) Bone marrow}

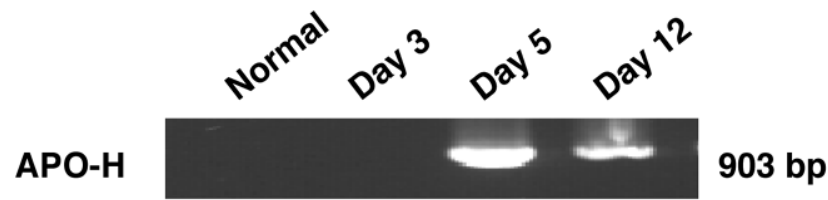

$\beta$-actin

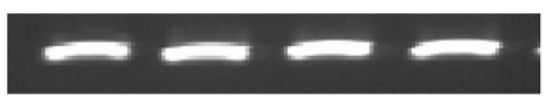
$500 \mathrm{bp}$ d)

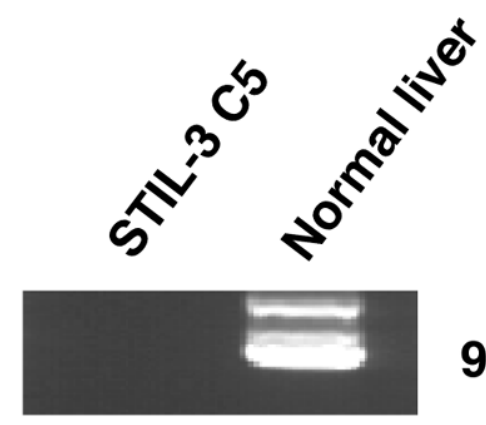

$903 \mathrm{bp}$

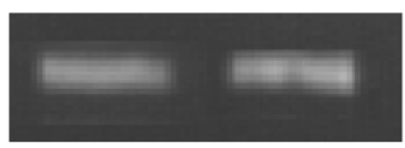

$500 \mathrm{bp}$

Fig. 6. PCR analysis of APO-H gene expression in L8313 leukemia bearing mice. The APO-H gene expression in vivo was examined by nested-PCR method using L8313 leukemic liver (a), spleen (b) and total bone marrow cells (c). PCR cycles for the detection of the amplified cDNA of $\beta$-actin and APO$\mathrm{H}$ were 30 cycles amplification. STIL-3 C5 cells was used as negative control of the APO-H production in the L8313 leukemic tissues (d).

of damaged cells. However, the physiological function of APO-H is not well understood.

Nonaka et al. reported that the mRNA expression of APO-H was detected in the liver, but not in the kidney, heart, spleen, lung or brain (Nonaka et al., 1992). We detected the APO-H gene expression in STIL-C5-CM stimulated bone marrow by nested-PCR (Fig. 5). Moreover, APO-H gene expression was detected in STIL-3 C5-CM stimulated fraction (Fr.) 2. Fr. 2 is rich in hematopoietic stem cell and progenitors (Sugiura et al., 1988), suggesting the possibility that the APO-H is NIL-3, and that it might be produced by IL-3 receptor positive hematopoietic progenitors and/or hematopoietic stem cells in cycle.

L8313 leukemia bearing mice show marked granulocytosis and splenomegaly, and a large number of IL-3 producing leukemic T-cells were detected in the liver of L8313 leukemia bearing mice (Aramaki et al., 1990). Accordingly, the gene expression of APO-H in vivo was examined by nestedPCR using the liver, spleen and the total bone marrow of L8313 leukemia bearing mice.

The APO-H gene expression was induced not only in the bone marrow but also in the liver and the spleen. Since the culture supernatant of these organs had high levels of IL-3 activity (Aramaki et al., 1990), it could be considered that the APO-H gene expression was induced in response to excess stimuli of IL-3 produced by infiltration of leukemic Tcells into these organs. The low NIL-3 activity of the L8313 leukemic spleen (Sugimoto et al., 1997) appears to be the result of the presence of a smaller number of hematopoietic stem cells in the spleen compared to that in the bone marrow. The APO-H protein was constitutively produced from the normal liver, and the enhanced gene expression was observed in the L8313 leukemic liver (Fig. 6a and b).

Recombinant APO-H showed low NIL-3 activity (Fig. 8) by DA-1 cell proliferation assay. The native APO-H is a highly glycosylated protein whereas recombinant APO-H lacks a part of the glycosylation. Therefore, this result was thought to be caused by the difference of posttranslational glycosylation in the host insect Sf9 cells. When the purified recombinant APO-H was electrophoresed, a few extra bands were found in silver stained gel except $45 \mathrm{kDa}$ protein (Fig. 7). These extra bans appear to be a result of the interaction of recombinant protein with host cellular proteins, because APO-H binds to various negatively charged sub- 


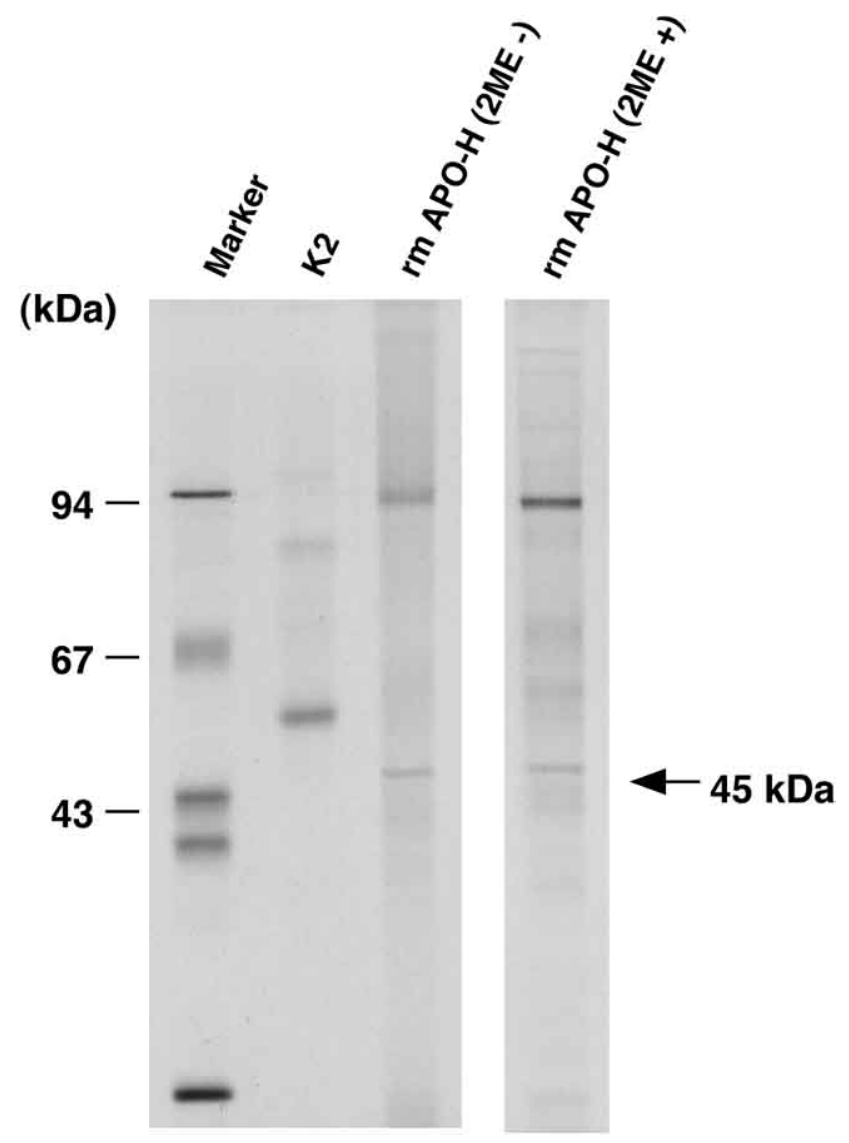

Fig. 7. SDS-PAGE of recombinant NIL-3 containing sample. SDSPAGE of purified recombinant APO-H was carried out in 10\% polyacrylamide gel. The purified K2 sample, low molecular weight marker and recombinant protein sample were applied at $100 \mathrm{ng} / \mathrm{lane}$, and the electrophoresed gel was silver-stained.

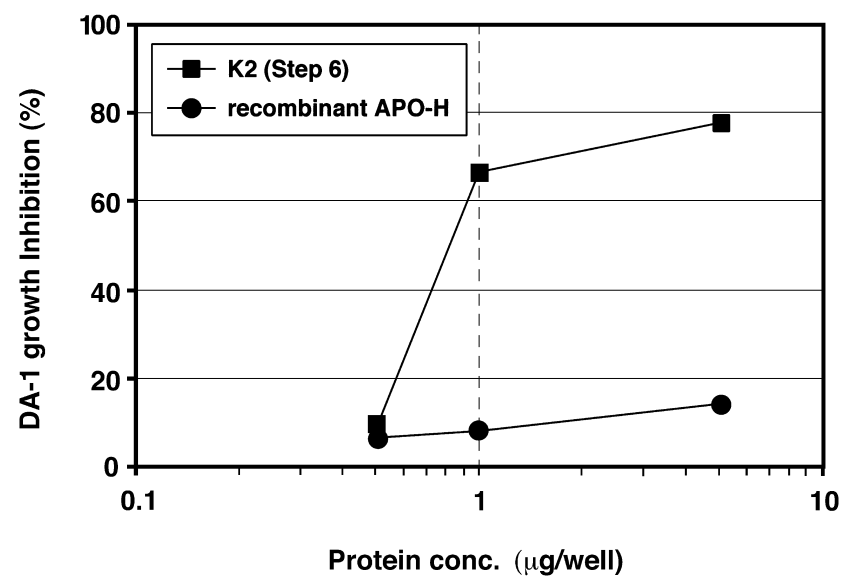

Fig. 8. Dose vs. inhibitory effect of purified recombinant protein on the DA-1 cell proliferation assay. Effect of NIL-3 activity of purified K2 and recombinant APO-H sample on the growth of IL-3 dependent DA-1 cells was tested. Results are expressed as a percentage (mean, $n=3$ ) of STIL-3 C5-CM stimulated positive control group. stances, as described above.

NIL-3 activity was also detected in other fractions except $\mathrm{K} 2$ on gel filtration chromatography (Fig. 2a and b). The expression of NIL-3 activity by APO-H may need another factors which enhances NIL-3 activity of APO-H, because recombinant murine APO-H derived of Sf9 cells does not contain such factors. Recombination of murine APO-H in mammalian cells is very important for the investigation of such factors while a number of negative regulators have recently been reported, almost all of these factors were tissue or cell extract and not always specific to a particular cell lineage. In contrast, NIL-3 is produced from bone marrow cells only in response to excess IL-3 stimulation, and it acts to suppresses the IL-3 activity in a dose dependent manner. Thus, NIL-3 (APO-H) appears to be one of physiological negative feedback regulators of IL-3 in bone marrow.

Acknowledgments. This work was supported in part by a Grant-in Aid for Scientific Research from the Ministry of Education, Science and Culture of Japan, by the Kato Memorial Bioscience Foundation, Japan and by the Saneyoshi Scholarship Foundation (No. 0504), Japan. The work was also supported by grants from KIRIN Brewery Co., LTD. and SANKYO Co., LTD.

\section{References}

Aramaki, K., Takayama, N., Taniguchi, S., Miyashita, M., Sugimoto, K., and Mori, K.J. 1990. Distribution of IL-3 activity in mice transplanted with IL-3 producing T cells (STIL-3): abrogation of the distribution of STIL-3 cells into the liver and liver hemopoiesis by splenectomy. Biomed. Pharmacother, 44: 429-434.

Axelrad, A.A., Croizat, H., and Eskinazi, D. 1981. A washable macromolecule from Fv2rr marrow negatively regulates DNA synthesis in erythropoietic progenitor cells BFU-E. Cell, 26: 233-244.

Broxmeyer, H.E., Bognacki, J., Dorner, M.H., and de Sousa, M. 1981. Identification of leukemia-associated inhibitory activity as acidic isoferritins. A regulatory role for acidic isoferritins in the production of granulocytes and macrophages. J. Exp. Med., 153: 1426-1444.

Broxmeyer, H.E., Gentile, P., Cooper, S., Lu, L., Juliano, L., Piacibello, W., Meyers, P.A., and Cavanna, F. 1984. Functional activities of acidic isoferritins and lactoferrin in vitro and in vivo. Blood. Cells, 10: 397426.

Broxmeyer, H.E., Williams, D.E., Lu, L., Cooper, S., Anderson, S.L., Beyer, G.S., Hoffman, R., and Rubin, B.Y. 1986. The suppressive influences of human tumor necrosis factors on bone marrow hematopoietic progenitor cells from normal donors and patients with leukemia: synergism of tumor necrosis factor and interferon-gamma. J. Immunol., 136: 4487-4495.

Carter, D.B., Deibel, M.R., Jr., Dunn, C.J., Tomich, C.S., Laborde, A.L., Slightom, J.L., Berger, A.E., Bienkowski, M.J., Sun, F.F., McEwan, R.N., Harris, P.K.W., Yem, A.W., Waszak, G.A., Chosay, J.G., Sieu, L.C., Hardee, M.M., Zurcher-Neely, H.A., Reardon, I.M., Heinrikson, R.L., Truesdell, S.E., Shelly, J.A., Eessalu, T.E., Taylor, B.M., and Tracy, D.E. 1990. Purification, cloning, expression and biological characterization of an interleukin-1 receptor antagonist protein. Nature, 344: 633-638.

de Larco, J.E. and Todaro, G.J. 1978. Growth factors from murine sarcoma virus-transformed cells. Proc. Natl. Acad. Sci. USA, 75: 40014005.

Delorme, D. and Daniels, E. 1992. Effects of interleukin-3 on murine fetal 
liver hemopoiesis in utero. Biol. Neonate., 62: 337-350.

George, J., Shoenfeld, Y., and Harats, D. 1999. The involvement of beta2glycoprotein I (beta2-GPI) in human and murine atherosclerosis. $J$. Autoimmun., 13: 57-60.

Goldwasser, E., Ihle, J.N., Prystowsky, M.B., Rich, I., and van Zant, G. 1983. The effect of interleukin 3 on hemopoietic precursor cells. In Normal neoplastic hemopoiesis. (Eds. D. Golde, P. Marks and C. F. Fox). Alau Liss, New York, pp381.

Graham, G.J., Wright, E.G., Hewick, R., Wolpe, S.D., Wilkie, N.M., Donaldson, D., Lorimore, S., and Pragnell, I.B. 1990. Identification and characterization of an inhibitor of haemopoietic stem cell proliferation. Nature, 344: 442-444.

Hannum, C.H., Wilcox, C.J., Arend, W.P., Joslin, F.G., Dripps, D.J., Heimdal, P.L., Armes, L.G., Sommer, A., Eisenberg, S.P., and Thompson, R.C. 1990. Interleukin-1 receptor antagonist activity of a human interleukin-1 inhibitor. Nature, 343: 336-340.

Holley, R.W., Bohlen, P., Fava, R., Baldwin, J.H., Kleeman, G., and Armour, R. 1980. Purification of kidney epithelial cell growth inhibitors. Proc. Natl. Acad. Sci. USA, 77: 5989-5992.

Igarashi, M., Matsuura, E., Igarashi, Y., Nagae, H., Ichikawa, K., Triplett, D.A., and Koike, T. 1996. Human beta2-glycoprotein I as an anticardiolipin cofactor determined using mutants expressed by a baculovirus system. Blood, 87: 3262-3270.

Ihle, J.N. 1985. Biochemical and biological properties of interleukin-3: a lymphokine mediating the differentiation of a lineage of cells that includes prothymocytes and mastlike cells. Contemp. Top Mol. Immunol., 10: $93-119$.

Ihle, J.N. and Askew, D. 1989. Origins and properties of hematopoietic growth factor-dependent cell lines. Int. J. Cell Cloning, 7: 68-91.

Lenfant, M., Sotty, D., Wdzieczak-Bakala, J., Itoh, K., Shirata, K., Sugimoto, K., and Mori, K.J. 1989. Suppression of mast cell colony formation by a low molecular weight fraction of fetal calf bone marrow extract. Leuk. Res., 13: 1085-1089.

Li, Q. and Congote, L.F. 1991. Isolation and characterization of three inhibitors of thymidine incorporation into bovine fetal liver cells. Ann. NY Acad. Sci., 628: 241-249.

Lord, B.I., Mori, K.J., Wright, E.G., and Lajtha, L.G. 1976. Inhibitor of stem cell proliferation in normal bone marrow. Br. J. Haematol., 34: 441-445.

McNeil, H.P., Simpson, R.J., Chesterman, C.N., and Krilis, S.A. 1990. Anti-phospholipid antibodies are directed against a complex antigen that includes a lipid-binding inhibitor of coagulation: beta 2-glycoprotein I (apolipoprotein H). Proc. Natl. Acad. Sci. USA, 87: 4120-4124.

Metcalf, D. 1986. The molecular biology and functions of the granulocytemacrophage colony-stimulating factors. Blood, 67: 257-267.

Miyashita, M., Sugimoto, K., Suzuki, J., Taniguchi, S., Aramaki, K., and Mori, K.J. 1991. Hierarchical regulation of interleukin production: induction of interleukin 6 (IL-6) production from bone marrow cells and marrow stromal cells by interleukin 3 (IL-3). Leuk. Res., 15: 1125-1131.

Nonaka, M., Matsuda, Y., Shiroishi, T., Moriwaki, K., and NatsuumeSakai, S. 1992. Molecular cloning of mouse beta 2-glycoprotein I and mapping of the gene to chromosome 11. Genomics, 13: 1082-1087.
Pluthero, F.G., Shreeve, M., Eskinazi, D., van der Gaag, H., Huang, K.S., Hulmes, J.D., Blum, M., and Axelrad, A.A. 1990. Purification of an inhibitor of erythroid progenitor cell cycling and antagonist to interleukin 3 from mouse marrow cell supernatants and its identification as cytosolic superoxide dismutase. J. Cell Biol., 111: 1217-1223.

Reid, K.B. and Day, A.J. 1989. Structure-function relationships of the complement components. Immunol. Today, 10: 177-180.

Sawada, H., Itoh, K., Kirikae, T., Sakoda, H., Tezuka, H., Kuribayashi, K. Maeda, M., Yoshida, Y., Uchino, H., Hanaoka, M., and Mori, K.J. 1988. Establishment of a hemopoietic stimulating factor producing murine leukemia cell lines: pathogenesis of granulocytosis in L8313 bearing mice. Leuk. Res., 12: 763-771.

Shoenfeld, Y., Harats, D., and George, J. 2000. Heat shock protein 60/65, beta 2-glycoprotein I and oxidized LDL as players in murine atherosclerosis. J. Autoimmun., 15: 199-202.

Spivak, J.L., Smith, R.R., and Ihle, J.N. 1985. Interleukin 3 promotes the in vitro proliferation of murine pluripotent hematopoietic stem cells. $J$. Clin. Invest., 76: 1613-1621.

Sugimoto, K., Jiang, H., Takashita, E., Inoue, H., Kadowaki, S., and Mori, K.J. 1997. Strain specific production of a negative regulator of IL-3 (NIL-3): difference in the negative feedback mechanism of hemopoiesis among mouse strains. Cell Struct. Funct., 22: 407-411.

Sugimoto, K., Taniguchi, S., Ogata, H., Ikehara, S., Fujita, J., and Mori, K.J. 1992. Production of a negative regulator of IL-3 by bone marrow cells in response to the supernatant of IL-3-producing STIL-3 leukemia cells. Leuk. Res., 16: 889-897.

Sugiura, K., Inaba, M., Ogata, H., Yasumizu, R., Inaba, K., Good, R.A., and Ikehara, S. 1988. Wheat germ agglutinin-positive cells in a stem cell-enriched fraction of mouse bone marrow have potent natural suppressor activity. Proc. Natl. Acad. Sci. USA, 85: 4824-4826.

Tokunaga, K., Taniguchi, H., Yoda, K., Shimizu, M., and Sakiyama, S. 1986. Nucleotide sequence of a full-length cDNA for mouse cytoskeletal beta-actin mRNA. Nucleic Acids. Res., 14: 2829.

Tsuji, T., Sugimoto, K., Yanai, T., Takashita, E., and Mori, K.J. 1994. Induction of granulocyte-macrophage colony-stimulating factor (GM$\mathrm{CSF}$ ) and granulocyte colony-stimulating factor (G-CSF) expression in bone marrow and fractionated marrow cell populations by interleukin 3 (IL-3): IL-3-mediated positive feedback mechanisms of granulopoiesis. Growth Factors, 11: 71-79.

Tucker, R.F., Shipley, G.D., Moses, H.L., and Holley, R.W. 1984. Growth inhibitor from BSC-1 cells closely related to platelet type beta transforming growth factor. Science, 226: 705-707.

Wolf, N.S. 1979. The haemopoietic microenvironment. Clin. Haematol., 8: 469 .

Wolpe, S.D. and Cerami, A. 1989. Macrophage inflammatory proteins 1 and 2: members of a novel superfamily of cytokines. Faseb. J., 3: 25652573.

Yoshida, Y. and Seki, M. 1985. Leukemic and hemopoietic microenvironment. J. Soc. Res., 25: 62.

(Received for publication, November 12, 2001

and in revised form, February 4, 2002) 